\title{
Bulletin of
}

Volume 111

Issue 4

August 2021

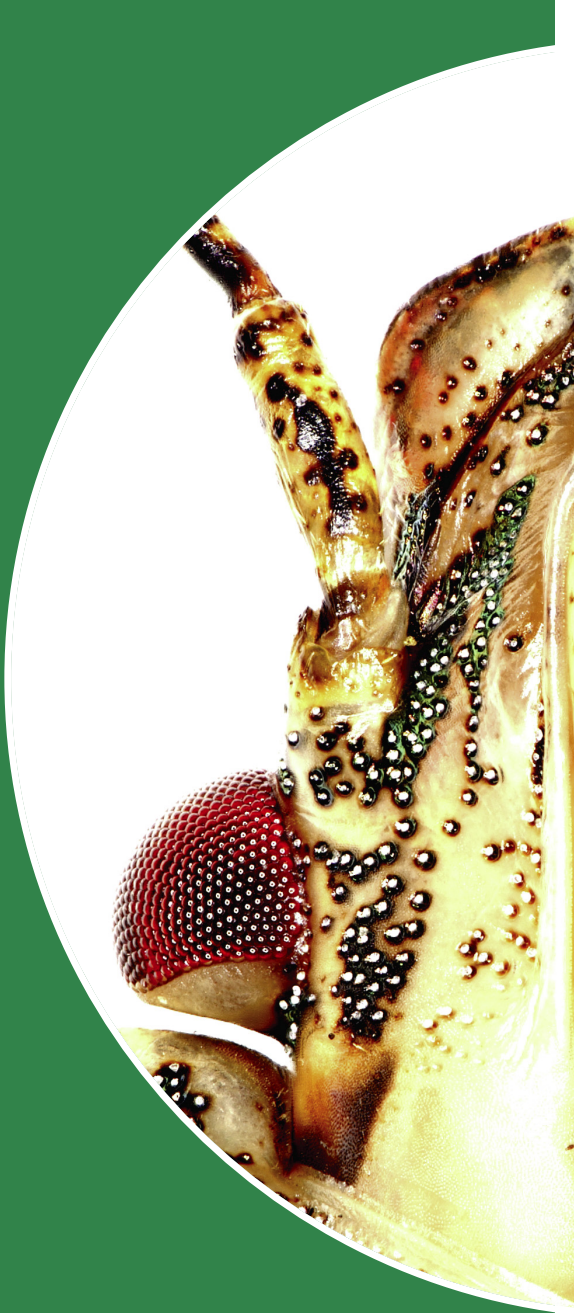

CAMBRIDGE

UNIVERSITY PRESS

Entomological Research

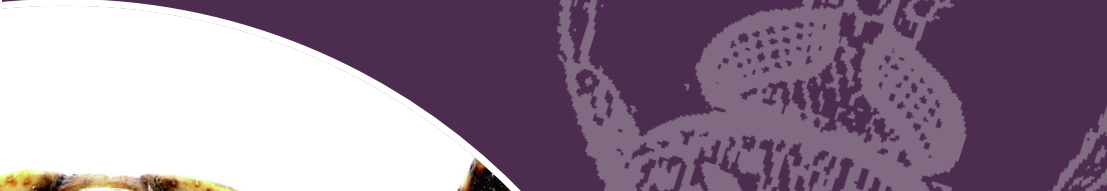




\title{
Bulletin of Entomological Research journals.cambridge.org/ber
}

\begin{abstract}
Aims and Scope
Established in 1910, the internationally recognised Bulletin of Entomological Research aims to further global knowledge of entomology through the generalisation of research findings rather than providing more entomological exceptions. The Bulletin publishes high quality and original research papers, 'critiques' and review articles concerning insects or other arthropods of economic importance in agriculture, forestry, stored products, biological control, medicine, animal health and natural resource management. The scope of papers addresses the biology, ecology, behaviour, physiology and systematics of individuals and populations, with a particular emphasis upon the major current and emerging pests of agriculture, horticulture and forestry, and vectors of human and animal diseases. This includes the interactions between species (plants, hosts for parasites, natural enemies and whole communities), novel methodological developments, including molecular biology, in an applied context. The Bulletin does not publish the results of pesticide testing or traditional taxonomic revisions.
\end{abstract}

Bulletin of Entomological Research is published bimonthly by
Cambridge University Press

\author{
Editor-in-Chief \\ Dr Paul De Barro \\ CSIRO Health \& Biosecurity, Brisbane, \\ Queensland 4001, Australia \\ Email:entomology@cambridge.org
}

\section{Subject Editors}

Dr Jonas Arnemann, Universidade Federal de Santa Maria, Brazil

Dr T. Backeljau, Royal Belgian Institute of Natural Sciences, Belgium

Dr L. Boykin, University of Western Australia, Australia

Dr D. Bray, University of Greenwich, UK

Professor M. Chen, Northwest AEF University, China Professor X-X. Chen, Zhejiang University, China

Dr S. Downes, CSIRO, Ecosystem Sciences, Australia

Dr A. K-W. Hee, Universiti Putra Malaysia, Malaysia

Dr H. Hesketh, Centre for Ecology and Hydrology, UK

Dr B. Hoffmann, CSIRO, Australia

Professor X-Y Hong, Nanjing Agricultural University, China

Dr T.H. Jones, Cardiff University, UK

Dr A. Kapranas, Benaki Phytopathological Institute, Greece

Dr E. Kistner-Thomas, USDA Midwest Climate Hub, USA

Dr D. Kriticos, CSIRO Black Mountain Labs, Australia

Dr O. Kwon, Kyungpook National University, South Korea

Dr S. Lawson, University of the Sunshine Coast, Australia

Professor C-Y. Lee, Universiti Sains Malaysia, Malaysia

Dr N. V. Meyling, University of Copenhagen, Denmark

Professor B. Nault, Cornell University, USA

Dr Michael Otim, National Crops Resources Research Institute, Uganda

Dr M. Pappas, Democritus University of Thrace, Greece
Dr D. Perez-Staples, INBIOTECA, Universidad Veracruzana, Mexico

Dr C. Phillips, AGResearch, New Zealand

Dr E. Roditakis, National Agricultural Research Foundation, Greece

Dr D. Segura, National Institute of Agricultural Technology (INTA), Argentina

Dr Z. Sheng, University of Chicago, USA

Professor P. Stevenson, Royal Botanic Gardens, Kew, UK

Professor J-H. Sun, Institute of Zoology, Chinese Academy of Sciences, China

Dr W.T. Tay, CSIRO Black Mountain Labs, Australia

Professor A. Tena, Valencian Institute for Agricultural Research, IVIA, Spain

Dr L. Thomson, University of Melbourne, Australia

Professor P. Trematerra, University of Molise, Italy

Dr B. Trewin, CSIRO, Australia

Dr M. Virgilio, Royal Museum for Central Africa, Belgium

Professor X.-W. Wang, Zhejiang University, China

Dr S. L. Wee, Universiti Kebangsaan Malaysia, Malaysia

Dr C. Weldon, University of Pretoria, South Africa

Dr S. Yang, Research Institute for Sustainable Humanosphere (RISH), Kyoto University, Japan

Dr M. Yazdani, University of Adelaide, Australia

Professor W. Zhang, Sun Yat-sen University, China

Dr Fang Zhu, Penn State University, USA

(c) Cambridge University Press 2021.

This journal issue has been printed on FSC $^{\mathrm{TM}}$-certified paper and cover board. FSC is an independent, non-governmental, not-for-profit organization established to promote the responsible management of the world's forests. Please see www.fsc.org for information.

Cover image: Halyomorpha halys (Hemiptera: Pentatomidae).

Photo taken by: Stefanie Fischnaller. 